\title{
Surface Roughness Effect on the Hydrophobicity Characteristic of Operating Composite Insulators
}

\author{
Song Wang \\ State Grid Beijing Electric Power Company \\ Beijing, China \\ e-mail: wangsongcq@139.com
}

\author{
Tian Yuan \\ China Electric Power Research Institute \\ Wuhan, China \\ e-mail: yuantian3@epri.sgcc.com.cn
}

\author{
Jun Zhou, Qian-yu Wang \\ College of Electrical Engineering \\ Wuhan University \\ Wuhan, China
}

\begin{abstract}
Pretreatment needs to be done before measuring the hydrophobicity of the composite insulators. However, the necessity of such pretreatment is questionable for operating composite insulators. Therefore, surface roughness of light pollution level, heavily pollution level, chalking and the impact of surface roughness on hydrophobicity characteristic (HC) was investigated in this paper. The paper does the research on the result indicated the surface roughness is one of main factor about the pretreatment effect on $\mathrm{HC}$ level and static contact angle. The pretreatment effect on $\mathrm{HC}$ level and static contact angle seemed to be very obvious and the percentage of static contact angle changed up to $15.3 \%$, as the surface roughness was varied. The $\boldsymbol{R}_{a}$ and $\boldsymbol{R}_{S M}$ of different pollution level shed percentage change up to $130 \%$ and $269 \%$. While $R_{a}$ and $R_{S M}$ of high surface roughness degree reach up to $3.242 \mu \mathrm{m}$ and $400 \mu \mathrm{m}$, the hydrophobicity on the composite insulators lost permanent. The surface roughness can lead the water drop to two kinds of states transitions and it can make sample static contact Angle changed up to $31 \%$ within 10 minutes, which will also cause the different results of two measurement methods. Surface roughness of composite insulators was suggested as the added parameter in hydrophobicity tests.
\end{abstract}

Keywords- hydrophobicity; operating composite insulators; surface roughness; static contact angle; HC levels test

\section{INTRODUCTION}

The excellent hydrophobicity of composite insulators makes the contamination resistance in high performance. Compared to porcelain and glass insulators, the hydrophobicity characteristic of composite insulators make small water drops, instead of water film in humid environment, condensed on the surface, which will greatly improve surface resistance of composite insulator beyond doubt. As to wet flashover and pollution flashover of transmission line, the critical voltage in industrial frequency will increase while times will decrease significantly. Thus it can be seen that this characteristic has an important value to ensure the long-term safety and reliability of transmission lines.
Through the examination, hydrophobicity decreases after the pollution flashover accidents of operating composite insulators [1]. As a result, hydrophobicity should be measured according to DL/T 864-2004, in order to replace the insulators in time before hydrophobicity decreases to level HC6. On-site measurement is difficult due to the environmental limit, so the hydrophobicity experiment should be temporarily performed in laboratory. The hydrophobicity characteristics experiment is mainly divided into three parts: classification, recovery and migration.

The silicon rubber jacket is covered with pollution and pulverized powder during the on-site operation, so pretreatment need to be carried out to remove the pollution so as to measure the hydrophobicity of silicon rubber itself. However, the measured results before and after the pretreatment varied a lot. For measurement aims to grasp the hydrophobicity state of composite insulators timely, in-lab hydrophobicity experiment should be performed on the surface within the same practical operating state. In order to analyze the impact of different surface states of silicon rubber jacket on hydrophobicity, in this paper, surface roughness is chosen as a quantifiable parameter to denote the characterization for different degree of pollution and pulverized powder attached to the surface of silicon rubber jacket, as well as pretreatment effect. Introduction of surface roughness measurement can not only provide the basis for hydrophobic classification method, but also remind testers measuring errors due to surface roughness changes which make static contact angle method and hydrophobic sizing method not equivalent. At present, domestic and overseas researches on hydrophobic are mainly concentrated in classification, recovery and migration, while surface roughness of operating composite insulators received less attention.

This paper starts from experimental research about whether the pretreatment of hydrophobic measurement is influential to hydrophobic characteristic of composite insulators, analyzes the relationship between hydrophobic changes and various surface roughness caused by pretreatments, also studies the impact of several types of 
rubber jacket surface roughness under different pollution situations on hydrophobic characteristics. On this basis, modification suggestions of hydrophobic measurement method referred to DL/T 864-2004 were put forward. The purpose is to make hydrophobic measurement and evaluation methods precisely evaluate the practical operation states of operating composite insulators.

\section{The Surface Roughness Measuring Method}

Surface profile method was commended in this paper as the surface roughness measuring method. Surface profile is the intersection between plane and actual surface as shown in fig.1. The measuring method is to detect the surface of composite insulators using a stylus in order to obtain the surface profile and calculating parameters.

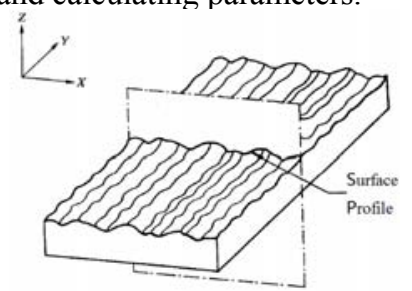

Figure 1. Surface Profile

Where surface profile parameters include amplitude, distance, hybrid, curve and related parameters. This paper focuses on the amplitude parameters and distance parameters. As the profile peak and profile valley of the composite insulator surfaces are randomly distributed, amplitude parameters can be denoted as $R_{a}$ using the arithmetic mean between sampling lengths of profile peak and profile valley showed below:

$$
R_{a}=\frac{1}{l} \int_{0}^{1}|Z(x)| d x,
$$

where $l$ denotes the sampling length, $Z(x)$ denotes the vertical coordinate.

Meanwhile, distance parameters can be denoted as $R_{S M}$ using the mean value of profile element width within sampling length $X_{S}$ as shown in fig.2:

$$
R_{S M}=\frac{1}{m} \sum_{i=1}^{m} X_{S_{i}},
$$

where $X_{S i}$ denotes the width of $i_{t h}$ unit, $\mathrm{m}$ denotes the number of profile element width within sampling length. Profile element is the combination of profile peak and profile valley.

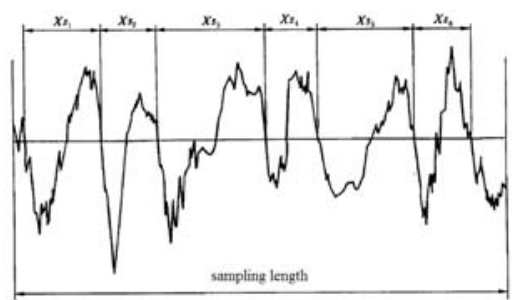

Figure 2. Profile Element Width $X_{S}$
During the experiment, surface roughness of each rubber jacket should be taken as the mean value of three times measurements, and the stylus force should be less than $0.5 \mathrm{~N}$.

\section{Testing EQUiPMENT AND SAMPLES}

Under the requirements of the relevant standards [3], watering can is chosen in hydrophobic classification method (HC). Hydrophobic Angle measurement uses optical contact Angle measuring system of type CAM200. In addition, type A Shore durometer is selected, so as type TR-200 surface roughness instrument shown in Fig. 3 and the sampling length is set as $0.8 \mathrm{~mm}$.

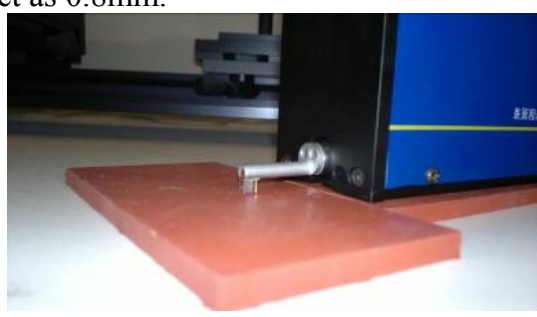

Figure 3. Surface Roughness Instrument

In this paper, 15 operating composite insulators are chosen from 12 different voltage grade lines various from $100 \mathrm{kV}$ to $500 \mathrm{kV}$ in 12 different provinces, where operating environment includes eight typical climate regions [1], and five major domestic manufacturers are contained. Sampling points of rubber jacket are all on the high voltage terminal.

\section{TEST RESUlts AND ANALysis}

\section{A. Hydrophobic Characteristic and Static Contact Angle} Before and After the Pretreatment of Rubber Jacket [4]

There are two different opinions in electric power industry about whether pretreatment should be required on the surface of rubber jacket during hydrophobic measurement: some people think that pretreatment is needed to reduce the interference of pollution for hydrophobic measurement; while others hold that in order to master the hydrophobic characteristic of operating composite insulators, pretreatment is not required so as to keep the surface state of rubber jacket the same as practical operation.

In this paper, half the surface of every rubber jacket gets pretreated while other half remains the same, and the results of hydrophobicity test are presented in tab.1. In this table, A1, A6, A9, A14, A15 are operating in the light pollution level (equivalent salt deposit density is lower than $0.006 \mathrm{mg} / \mathrm{cm}^{2}$, non-soluble deposit density is lower than $0.2 \mathrm{mg} / \mathrm{cm}^{2}$ ); A2, A3, A4, A5, A8, A10, A11, A12 are operating in the heavy pollution level (ESDD is lower than $0.05 \mathrm{mg} / \mathrm{cm}^{2}$, NSDD is lower than $0.5 \mathrm{mg} / \mathrm{cm}^{2}$ ); A7, A13 are operating in chalking composite insulators (ESDD is lower than $0.02 \mathrm{mg} / \mathrm{cm}^{2}$, NSDD is lower than $1.0 \mathrm{mg} / \mathrm{cm}^{2}$ ). 
TABLE I. RESULTS OF HYDROPHOBICITY TEST

\begin{tabular}{|c|c|c|c|c|c|}
\hline \multirow{2}{*}{} & \multicolumn{2}{|c|}{$\begin{array}{c}\text { Hydrophobic } \\
\text { Classification }\end{array}$} & \multicolumn{2}{c}{ Static Contact Angle } & \multirow{2}{*}{ Shore A } \\
\cline { 2 - 5 } & Pretreated & No & Pretreated & No & \\
\hline A1 & HC3 & HC4 & 121.2 & 118.8 & 65 \\
\hline A2 & HC6 & HC2 & 140.5 & 133.1 & 47 \\
\hline A3 & HC1 & HC2 & 126.6 & 125.2 & 58 \\
\hline A4 & HC2 & HC6 & 126.4 & 129.7 & 70 \\
\hline A5 & HC2 & HC1 & 121.6 & 134.3 & 67 \\
\hline A6 & HC2 & HC1 2 & 131.9 & 136.3 & 62 \\
\hline A7 & HC5 & HC2 & 110.6 & 119.8 & 53 \\
\hline A8 & HC6 & HC6 & 111.8 & 128.9 & 38 \\
\hline A9 & HC2 & HC2 & 119.9 & 128.8 & 62 \\
\hline A10 & HC2 & HC2 & 125.7 & 128.0 & 65 \\
\hline A11 & HC3 & HC1 & 122.6 & 131.6 & 45 \\
\hline A12 & HC2 & HC1 & 131.9 & 115.4 & 48 \\
\hline A13 & HC6 & HC1 & 118.5 & 123.7 & 62 \\
\hline A14 & HC1 & HC1 & 113.4 & 115.8 & 50 \\
\hline A15 & HC1 & HC1 & 114.6 & 113.9 & 52 \\
\hline
\end{tabular}

From the above table it can be seen that: the hydrophobic classification results with and without pretreatment are opposite, and the static contact angles differ $15.3 \%$, fully illustrated the great impact of pretreatment on hydrophobic classification and static contact angle. Meanwhile, there exists a certain relationship between hardness and its change tendency. As a result, we suggest that pretreatment is not required in hydrophobic measurement of composite insulators. Otherwise, the results cannot match the practical operation state.

\section{B. Roughness Comparison Before and After Pretreatment of Rubber Jacket}

Results of roughness test before and after the pretreatment of rubber jacket using type TR-200 surface roughness instrument are listed below.

TABLE II. RESUlts OF SURface Roughness TEST

\begin{tabular}{|c|c|c|c|c|}
\hline \multirow{2}{*}{} & \multicolumn{2}{|c|}{ Pretreatment } & \multicolumn{2}{c|}{ Without Pretreatment } \\
\cline { 2 - 5 } & $\boldsymbol{R}_{\boldsymbol{a}}$ & $\boldsymbol{R}_{\boldsymbol{S M}}$ & $\boldsymbol{R}_{\boldsymbol{a}}$ & $\boldsymbol{R}_{\boldsymbol{S M}}$ \\
\hline $\mathbf{A 1}$ & 0.764 & 119.2 & 0.893 & 146.8 \\
\hline $\mathbf{A 2}$ & 0.708 & 298.1 & 0.458 & 188.6 \\
\hline $\mathbf{A 3}$ & 0.885 & 140.2 & 0.911 & 204.3 \\
\hline $\mathbf{A 5}$ & 0.876 & 329.0 & 0.743 & 304.2 \\
\hline $\mathbf{A 6}$ & 0.804 & 193.5 & 0.758 & 169.7 \\
\hline $\mathbf{A 7}$ & 1.656 & 281.0 & 1.284 & 114.7 \\
\hline $\mathbf{A 8}$ & 0.677 & 162.8 & 0.586 & 147.9 \\
\hline $\mathbf{A 9}$ & 0.856 & 135.4 & 0.826 & 125.5 \\
\hline $\mathbf{A 1 0}$ & 0.494 & 212.8 & 0.594 & 132.1 \\
\hline $\mathbf{A 1 1}$ & 0.985 & 174.5 & 0.877 & 159.8 \\
\hline $\mathbf{A 1 2}$ & 0.799 & 258.4 & 0.533 & 146.4 \\
\hline $\mathbf{A 1 3}$ & 3.878 & 352.2 & 1.724 & 95.40 \\
\hline $\mathbf{A 1 4}$ & 0.296 & 75.5 & 0.311 & 64.40 \\
\hline $\mathbf{A 1 5}$ & 0.288 & 66.7 & 0.293 & 58.80 \\
\hline
\end{tabular}

a) Light Pollution Level

Before the pretreatment, $R_{a}$ was between $0.288 \mu \mathrm{m}$ to $0.876 \mu \mathrm{m}, R_{S M}$ was between $66.7 \mu \mathrm{m}$ to $193.5 \mu \mathrm{m}$, the surface profile is more uniform as shown in Fig.4. After the pretreatment, $R_{a}$ is between $0.293 \mu \mathrm{m}$ to $0.893 \mu \mathrm{m}, R_{S M}$ is between $66.7 \mu \mathrm{m}$ to $193.5 \mu \mathrm{m}$.

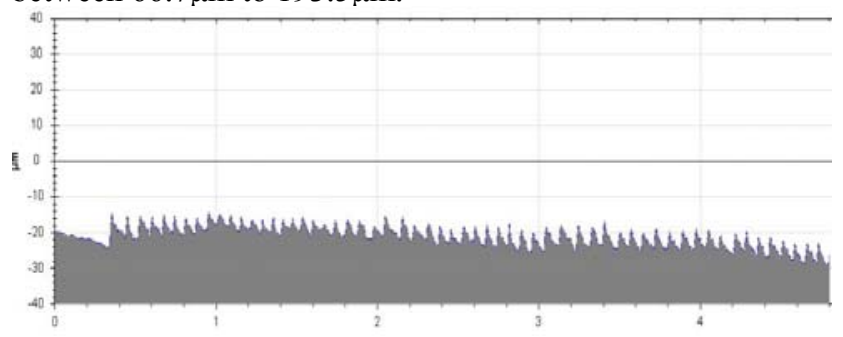

Figure 4. Surface Profile of Light Pollution Level

b) Heavy Pollution Level

Before the pretreatment, $R_{a}$ was between $0.458 \mu \mathrm{m}$ to $0.911 \mu \mathrm{m}, R_{S M}$ was between $125.5 \mu \mathrm{m}$ to $304.2 \mu \mathrm{m}$, the surface profile is more uniform as shown in Fig.4. After the pretreatment, $R_{a}$ is between $0.494 \mu \mathrm{m}$ to $0.985 \mu \mathrm{m}, R_{S M}$ is between $135.4 \mu \mathrm{m}$ to $329.0 \mu \mathrm{m}$.

c) Chalking Surface

The roughness measurement of seriously pulverized surface profile shows a deeper amplitude parameter $\left(R_{a}\right.$ is between $1.284 \mu \mathrm{m}$ to $1.724 \mu \mathrm{m})$, and a smaller distance parameter $\left(R_{S M}\right.$ is between $95.4 \mu \mathrm{m}$ to $\left.114.7 \mu \mathrm{m}\right)$. After the pretreatment, $R_{a}(1.656 \mu \mathrm{m} \sim 3.878 \mu \mathrm{m})$ and $R_{S M}(281.0 \mu \mathrm{m} \sim$ $352.2 \mu \mathrm{m})$ all have obvious increase.

Equation (3) is obtained though the data analysis of amplitude parameter variation $R_{a 1}$ and Shore A:

$$
R_{a l}=0.088 \ln (A)-0.1893
$$

$R_{a l}$ denotes the amplitude parameter variation $\left(R_{a}\right.$ before pretreatment minus $R_{a}$ after pretreatment). From equation (3) we can found out that after the pretreatment, roughness $R_{a}$ in high hardness value decreased, while $R_{a}$ in low hardness value increased. No matter how hard the chalking surface gets, there will be obvious changes before and after the pretreatment.

\section{Relationship between Surface Roughness and HC}

As we can see in Fig.5, there is an explicit relationship between hydrophobic classification measurement result and distance parameter $R_{S M}$.

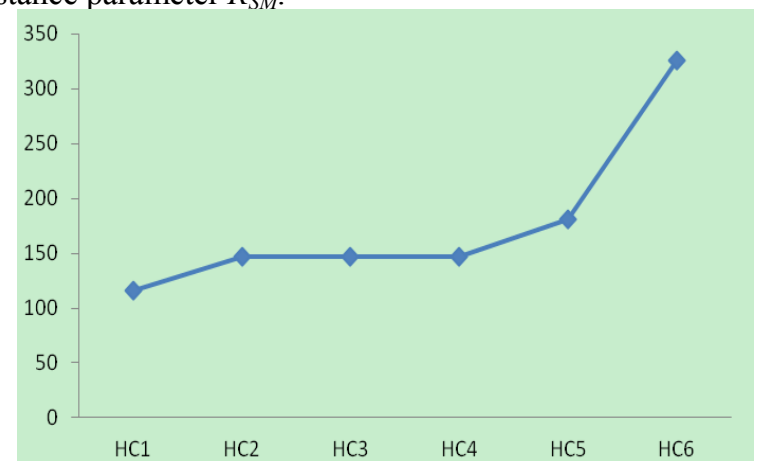

Figure 5. Relationship between HC Level and $R_{S M}$ 
However, relationship between HC level and amplitude parameter $R_{a}$ is not clear and disperses widely, so the rule similar to Fig. 5 cannot be display. After the comparison analysis of profile measured by surface roughness instrument, we think there are two main reasons lead to this phenomenon. Firstly, when the amplitude parameter of chalking surface $R_{a}$ is higher, surface crack is filled with superfine silica powder and dust. This will make $R_{S M}$ small enough to present homogeneous surface profile (shown in the left half of Fig.6 (a)), similar to light pollution surface (shown in Fig.4), which can prevent water drops from crossing the surface crack filled with superfine silica powder. As a result, the contact angle of ejecting water drops caused by HC level performed as Cassie model (principle is shown in Fig.6(c)) with a great hydrophobicity. Secondly, after the pretreatment (shown in Fig.6 (b)), powder filling the surface crack gets removed, amplitude parameter $R_{a}$ remains high while distance parameter $R_{S M}$ increases significantly, which lead the ejecting water drops move into surface crack with a poor hydrophobicity.

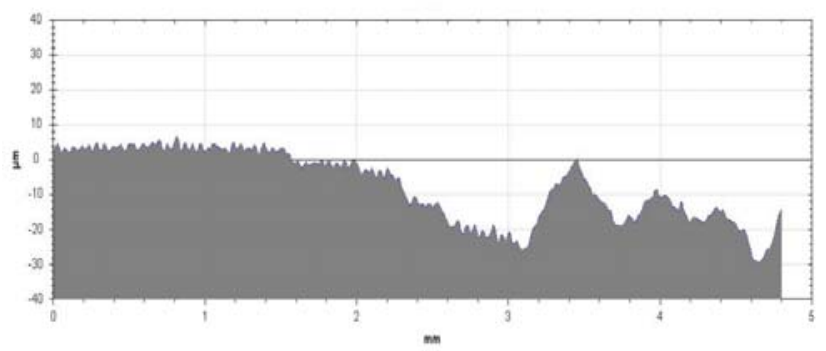

(a) Surface Roughness Profile of A13 (before pretreatment)

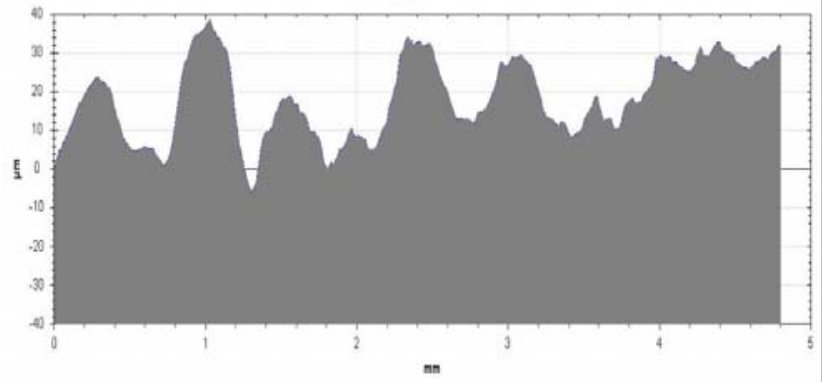

(b) Surface Roughness Profile of A13 (after pretreatment)

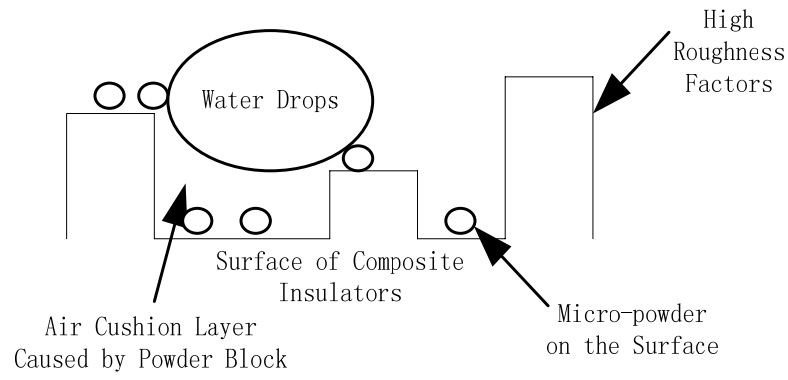

(c) Principle of Cassie Model

Figure 6. Analysis of Chalking Surface

\section{Relationship between High Surface Roughness and} Hydrophobic Classification

Sand paper was used on the sample surface to form a partial surface while $R_{a}=3.242 \mu \mathrm{m}$ and $R_{S M}=400 \mu \mathrm{m}$, as well as a static contact angle descent $89.0^{\circ} \sim 93.5^{\circ}$. Even when put it in the oven at temperature $30^{\circ} \mathrm{C}$ for 1 month, surface hydrophobicity cannot restore, while other parts of the sample can return to $\mathrm{HC} 1 \sim \mathrm{HC} 2$, as shown in fig. 7 .

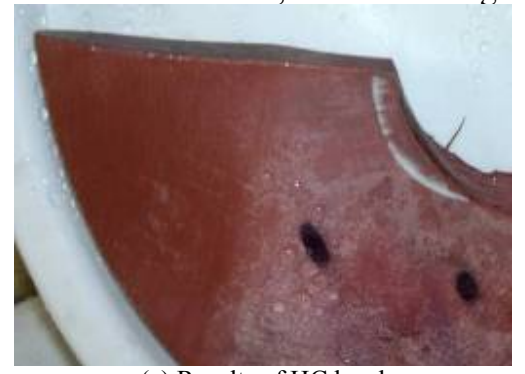

(a) Results of $\mathrm{HC}$ level

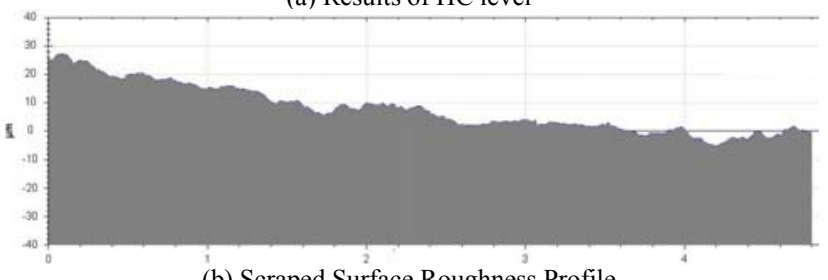

(b) Scraped Surface Roughness Profile

Figure 7. Hydrophobicity and Profile $\left(R_{a}=3.242 \mu \mathrm{m}\right)$

When roughness reaches a certain value $\left(R_{a} \geq 3.242 \mu \mathrm{m}\right.$, $R_{S M} \geq 400 \mu \mathrm{m}$ ), from the high roughness surface test, we can know that hydrophobicity of material itself cannot play a leading role. At this time, even though the silica hasn't aging, there exists no hydrophobicity.

\section{E. Impact of Roughness on Hydrophobic Recovery characteristic}

With or without pretreatment, hydrophobic recovery characteristic of rubber jacket differs a lot. After the pretreatment, hydrophobicity of some rubber jackets may recovery in $48 \mathrm{~h}$, while those without pretreatment can't. However, during the test, most static contact angles are greater than $90^{\circ}$, result in inconsistency. The surface roughness measurement showed us that, after immersing in deionized water for $96 \mathrm{~h}$, there are different degrees of increase in $R_{a}$. Those in high values increase a lot while those in low ones are smaller. It should be pointed out that, RSM shows no obvious change.

\section{F. Impact of Roughness on Hydrophobic Migration characteristic}

Inert material diatomite used in hydrophobic migration is between $106 \mu \mathrm{m} \sim 150 \mu \mathrm{m}$ in diameter, with which surface structure gets more complicated. Size, shape, adhesion and coating way of diatomite particle directly affect $R_{a}$ and $R_{S M}$, which will further influence the measurement results.

Most hydrophobicity of sample rubber jackets cannot migrate onto the surface (shown in Fig.8), while migration situation of new samples is better. 


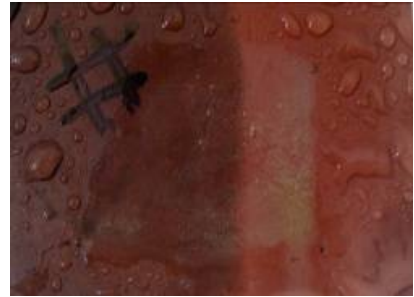

(a) HC Level Results

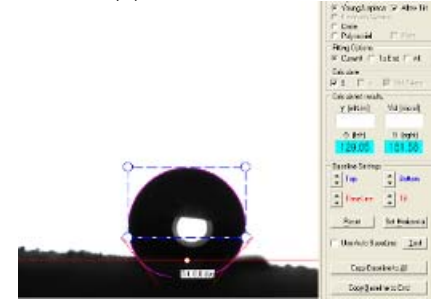

(b) Migrated Statics Contact Angle

Figure 8. Comparison of Statics Contact Angle in Hydrophobicity Migration

The above test results fully illustrate that surface roughness of composite insulators has a great influence on hydrophobic characteristic.

\section{RELATIONSHIP BETWEEN SURFACE ROUGHNESS AND Statics Contact ANGLE}

Statics contact angle method is one of the hydrophobicity measurements. During the tests, surface roughness will cause the following problems:

a. Surface roughness lead to obvious statics contact angle lag (shown in Fig.9 (a) and (b)), statics contact angle changed from $126.0^{\circ}$ in $10 \mathrm{~s}$ to $87.0^{\circ}$ in $10 \mathrm{~min}$.

Analysis [4] showed that this is the process classical Cassie model slowly transforming to Wenzel model (shown in Fig.9 (c) and (d)), phenomenon caused by various surface roughness.

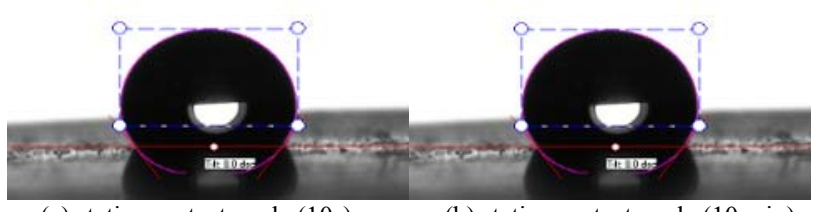

(a) statics contact angle (10s)

(b) statics contact angle (10 $\mathrm{min})$

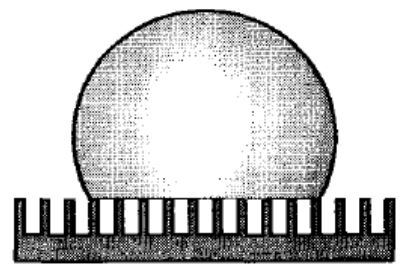

(c) Cassie model [2]

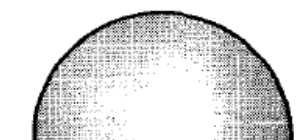

Щнинищи

(d) Wenzel model [2]

Figure 9. Statics Contact Angle Lag

$b$. Impact of roughness change on statics contact angle is smaller than HC level. Especially on high roughness surface, measurement results conflict.
Here is the reason. While statics contact angle is in Cassie model, it isn't affected by the amplitude parameter, statics contact angle change a little when roughness changes. On the high roughness surface, quantity and strength of ejecting water in $\mathrm{HC}$ level may change the Cassie model to Wenzel model, while statics contact angle remains in Cassie model. All these lead to the conflict. However, on smaller roughness surface, conflict will not be obvious.

$c$. Statics contact angle shows no classification function.

Under existing standards, $\theta_{\mathrm{av}} \geq 90^{\circ}, \theta_{\min } \geq 85^{\circ}$, just to meet the hydrophobicity $\left(\theta \geq 90^{\circ}\right.$ should be considered as the hydrophobic surface in chemical category).

\section{CONCLUSION}

a. Impact of surface roughness on hydrophobic characteristic of operating composite insulators is obvious, among which $\mathrm{HC}$ level results and distance parameter $R_{S M}$ have obvious corresponding relation, while corresponding relation with $R_{a}$ isn't ideal due to surface powder filling.

b. Roughness of rubber jacket varied before and after pretreatment, and the trends are all related to hardness. However, no matter how hard the chalking surface is, obvious changes will take place both before and after the pretreatment.

c. There are obvious changes in hydrophobicity and statics contact angle both before and after pretreatment of rubber jacket. As a result, pretreatment should not be put forward before the hydrophobicity measurement of operating composite insulators. Otherwise it will lead to the deviation of measurement results.

d. Measurement methods of statics contact angle and HC level is inequitable, which is common on high roughness surface. In that case, $\mathrm{HC}$ level is suggested for its similarity with operating conditions.

e. Surface roughness measurement is suggested in $\mathrm{HC}$ level to better correspond the $\mathrm{HC}$ hierarchical relationship and degree of aging on rubber jacket.

\section{REFERENCES}

[1] Yang Yingjian, Wu Guangya, Zhang Qin, Zhang Rui, Yuan Tian, etc. The researches about age of the composite insulators and RTV. WuHan State grid electrical power research institute, 2012:15-16.

[2] GB/T3505 Geometrical Product Specifications (GPS)-Surface texture: Profile method - Terms, definitions and surface texture parameters, Beijing: China Standard Press, 2000.

[3] DL/T864 Application guide of composite insulators for AC overhand lines with a nominal voltage over $1000 \mathrm{~V}$, Beijing:China Electric Power Press, 2004.

[4] SUI Tao, WANG Jiadao, CHEN Darong. Energy analysis for transition from Cassie state to Wenzel state. Journal of Chemical Industry and Engineering (China), 2011, 62(5): 1352-1357

[5] Guan Zhicheng, Liang xidong, Zhang RenYu, Chen Yuan. Hydrophobicity Life-span of Silicone Rubber Composite Insulator. HIGH VOLTAGE ENGINEERING, 1998, 24(1):6-8.

[6] Qu Ailan, WEN Xiufang, PI Pihui, CHENG Jiang, YANG Zhuoru. Study on Super hydrophobicity of Composite Silica Film Surface. Journal of Inorganic Materials, 2008,23(2), 377-378

[7] Wang Xiao-dong, Peng Xiao-feng. Self-aggregation of vapor-liquid phase transition [J] . Progress in Natural Science , 2003, 13 (6) :451456 
[8] Wang Xiaodong, Peng Xiaofeng, Lu Jian-feng, Wang Bu-xuan. Measuring Technique of Contact Angle and Contact Angle Hysteresis on Rough Solid Surfaces: Measuring Technique of Contact Angle. Journal Of basic Science and Engineering, 2003,11(2), 174-181.

[9] XU Tao, WU Guang-ya, ZHOU Wen-jun. Flashover Voltage Characteristic of $1000 \mathrm{kV}$ AC Transmission Line Insulator Strings Under Polluted Conditions. High Voltage Engineering, 2007, 33(7):913.

[10] WU Wei-ning, WU Guang-ya, ZHANG Rui Causation analysis and countermeasures of pollution flashover of transmission and distribution equipment[J]. High Voltage Engineering, 2004, 30(7), 911 .

[11] GB/T 19519. Composite insulators for a.c. overhead lines with a nominal voltage greater than $1000 \mathrm{~V}$ - Definitions, test methods and acceptance criteria, Beijing: China standard Press, 2004

[12] TANG Liangrui, ZHAO Chunhui, QI Bing. Hydrophobic Detection Based on Ant Colony Algorithm. High Voltage Engineering, 2009 35(6): 1322-1326

[13] TU Youping, TONG Yuliang, WANG Qian etc. Influence of Humidity on Ozone Aging Performance of HTV Silicon Rubber. High Voltage Engineering, 2011, 37(4), 844-846.

[14] LAN Lei, WANG hanliang, WEN xishan. Accelerated corona aging test analysis and lifetime prediction of HTV silicone rubber. High Voltage Engineering, 2012, 38(4), 782 789.

[15] XU Zhiniu, LV Fangcheng, LI Man, LI Ming-he. Study of Silicone Rubber Hydrophobicity Representation Method Using Dynamic Contact Angle. High voltage Apparatus, 2010, 46(10): 8-9.

[16] GAo Haifeng,W ANG Yongfu, ZHU Keneng, et. Analysis on effect of hydr0phobicity on anti-pollution flashover performance of line insulators[J]. High Voltage Engineering, 2011, 37(2): 284-289.

[17] LIANG Ying, LI Chengrong, DING Lijian, et a1. Effect of corona discharge on the hydrophobicity recovery of HTV silicone rubber[J]. High Voltage Engineering, 2008, 34(1): 30-40.
[18] DL/T810-2002 Technical specification for $\pm 500 \mathrm{kV}$ DC long rod composite insulators[s]. Beijing, China: China Electric Power Press, 2002.

[19] WANG Jianguo, LIU Yang, FANG Chunhua, etc. Performance influence of high temperature vulcanization silicone rubber by alternating current corona discharge $[\mathrm{J}]$. Acta Polymerica Sinica, 2009(4): 33-337.

[20] YANG Kai, ZHENG Nan, ZHANG Guanjun, et a1. Analysis of surface trapping parameters of solid insulation dielectric[J]. High Voltage Engineering, 2007, 33(9): 13-16.

[21] XU Zhiniu, Wang Guoli, ZHAO Lijuan, ZHAO Peng, WANG Gang, Static contact angle algorithm of hydrophobicity detection[J]. High Voltage Engineering, 2012, 38(8): 1891-1900.

[22] Jia Zhidong, Fang Su, Gao Haifeng, et a1. Development of RTV silicone coatings in China: overview and bIhliography[J]. IEEE Electrical Insulation Magazine, 2008, 24(2): 28-4I.

[23] Kevin E, James X, Weijun Y, et a1.Degradation of a silicone based coating in a substation application[J]. IEEE Transactions on Power Delivery, 1999, 14(1): 188-193.

\section{BIOGRAPHIES}

YUAN Tian was born in 1980, male, Ph.D. candidate. His engineer research direction is insulator testing and anticontamination of the lines.

ZHOU Jun was born in HuBei, China, on Nov 10, 1980. He received the B.S. degree and Ph.D. degree of high-voltage and insulation technology from Wuhan University, Wuhan, China. His major fields of interest are Power System Operation and Control and LCC technology. 